\title{
As Implicações Sociais da Deficiência Auditiva Adquirida em Adultos
}

Social Implications of Acquired Hearing Impairment in Adults

\author{
Madalena Aparecida Silva Francelin \\ Mestre em Saúde Pública. Assistente Social e Chefe de Seção \\ Técnica do Hospital de Reabilitação de Anomalias Craniofaciais \\ (HRAC/USP). \\ Endereço: Rua Silvio Marchione, 3-20, Caixa postal 620, CEP 17043- \\ 900, Bauru, SP, Brasil. \\ E-mail: madafranळcentrinho.usp.br \\ Telma Flores Genaro Motti \\ Doutora em Educação Especial. Assistente Técnica de Direção do \\ HRAC/USP-Bauru/SP. \\ Endereço: Rua Silvio Marchione, 3-20, Caixa postal 620, CEP 17043- \\ 900, Bauru, SP, Brasil. \\ E-mail: telmottiळcentrinho.usp.br

\section{Ione Morita} \\ Doutora em Ciências Sociais. Professora Assistente Doutora do \\ Departamento de Saúde Pública da Faculdade de Medicina de \\ Botucatu - Unesp. \\ Endereço: Distrito de Rubião Junior, CEP 18618-970, Botucatu, \\ SP, Brasil. \\ E-mail: imorita®fmb.unesp.br
}

\section{Resumo}

O objetivo deste estudo foi analisar as implicações da surdez adquirida em adultos, na vida familiar, social e no trabalho, com uma abordagem qualitativa. Foram selecionadas 27 pessoas residentes em Bauru-SP, com diagnóstico de perda auditiva de manifestação súbita na faixa etária de 18 a 60 anos, matriculados no Hospital de Reabilitação de Anomalias Craniofaciais (HRAC/USP) entre janeiro de 2000 e fevereiro de 2005 , sendo entrevistados 16 . Utilizaram-se a entrevista e a análise de conteúdo. Constatou-se: a perda auditiva ocorreu entre os 40 e 44 anos, 37,5\%; 62,5\% dos que perderam a audição eram do sexo masculino, $62,5 \%$ não tinham o ensino fundamental; 62,5\% eram da classe Baixa Superior; $75 \%$ apresentaram perda auditiva bilateral, $18,75 \%$ de grau moderado/profundo. Dos 13 que estavam trabalhando quando perderam a audição, 30,77\% pararam de trabalhar e 15,38\% mudaram de profissão. Foram relatadas situações como: afastamento do trabalho, demissão a pedido e demissão pelo empregador, dificuldade de aceitação, cobranças, falta de esclarecimentos e desconhecimento dos próprios profissionais de saúde. Os dados sugerem a necessidade dos recursos de reabilitação, de apoio terapêutico, respeito e alternativas de conhecimentos.

Palavras-chave: Deficiência auditiva; Exclusão; Relações familiares. 


\section{Abstract}

This study aimed at analyzing, by means of a qualitative approach, the implications of acquired deafness in adults with regard to family life, social life and work. Twenty-seven individuals residing in the city of Bauru, State of São Paulo, were selected. All of them had been diagnosed with hearing impairment of sudden onset at the age range of 18 to 60 years and were registered at the Hospital for Craniofacial Anomaly Rehabilitation (HRAC/USP) between January 2000 and February 2005. Sixteen of such individuals were interviewed, and content analysis was used. It was found that, for $37.5 \%$ of the subjects, hearing impairment occurred between the ages of 40 and 44 years; $62.5 \%$ were males; $62.5 \%$ had not completed elementary education; $62,5 \%$ belonged to the lower middle class; $75 \%$ presented bilateral hearing impairment, $18.75 \%$ presented moderate/profundo impairment. Of the 13 individuals who were employed when hearing impairment manifested itself, 30.77\% quit their jobs, and $15.38 \%$ changed their occupations. The following situations were reported: being on a sick leave from work, resignation from one's job, dismissal by employer, difficulty of acceptance, demands from others, and lack of clarification and knowledge on the part of health care professionals. The results suggest the need for rehabilitation resources, therapeutic support, respect and knowledge alternatives.

Keywords: Hearing Impairment; Exclusion; Family Relations.

\section{Introdução}

A deficiência auditiva é uma das principais deficiências físicas que acomete o indivíduo em qualquer fase da vida, implicando a quem a adquire limitações no desempenho de atividades sociais (Russo e Almeida, 1995). Pode ser classificada quanto à sua forma de manifestação, origem e gravidade de acordo com os graus leve moderado, severo e profundo.

As alterações da audição que ocorrem após o nascimento são ocasionadas por fatores genéticos ou não, podendo manifestar-se isoladamente ou associada a outras anormalidades. Dentre as principais etiologias relacionadas à perda brusca de audição estão as de origem inflamatória (virais, bacterianas, autoimunes e alérgicas), fatores vasculares, afecções neurológicas degenerativas, ototoxidade, tumores e traumas (Russo e Santos, 1993; Galindo, 2007).

As consequências desses rebaixamentos de limiares auditivos a partir do grau moderado podem ser amenizadas com o uso de recursos de amplificação sonora e, nos casos mais graves, pode ser associada à leitura orofacial e ao uso da língua de sinais (WHO, 2006a).

Esta pesquisa enfoca a deficiência auditiva de manifestação súbita, isto é, identificada em até 45 dias após sua ocorrência, em indivíduos de idade adulta e seus reflexos no ambiente social, na família e no trabalho, visando compreender o enfrentamento do meio, acolhendo ou excluindo essa população, uma vez que o ser humano, ao depender de seus sentidos para manter contato com o ambiente e receber estímulos, passa a ter uma grande restrição.

As estimativas da WHO (2006b), considerando a incidência de problemas auditivos, indicam que dois terços da população mundial vivem em países em desenvolvimento e essa situação tende a se agravar de acordo com as condições de vida e saúde. Além disso, não é o crescimento econômico, mas a forma como a riqueza é distribuída em um país que altera as condições de saúde da população.

No Brasil, esse quadro é agravado pelas desigualdades na distribuição da riqueza. Grande parte da população vive em situação de pobreza, sem acesso às condições mínimas de serviços de saúde (WHO, 2006c). 
De acordo com Passos (2004), 65\% das perdas auditivas são adquiridas, prevalência que vem aumentando devido à falta de prevenção de doenças infectocontagiosas, ou seja, mais de $50 \%$ dos casos poderiam ser evitados.

Dados do IBGE (200o) revelam que 3,3\% da população brasileira se declara incapaz, com alguma ou grande dificuldade permanente de ouvir, sendo que, desse total, $1,9 \%$ se encontra na faixa de 15 a 64 anos de idade. Essa população convive com um mundo que valoriza o trabalho para a reprodução social, o que é relacionado a um contingente de pessoas saudáveis.

O trabalho é um dos determinantes fundamentais das condições de vida e o sustento da maioria das pessoas, mas o trabalhador enfrenta as dificuldades da insuficiente oferta de emprego e do mercado de trabalho exigente, que visa à produção, deixando à margem aqueles que não produzem ou apresentam alguma deficiência física ou mental (Morita, 2005; Souza e Neves, 2005).

Para Marin e Góes (2006), a deficiência auditiva tem mais importância em como as relações sociais são construídas ou significadas, ou seja, como a pessoa é falada, olhada e julgada. O local de trabalho, sendo um espaço com predomínio da língua oral, dificulta ao surdo mostrar seu potencial, e ele pode falhar no cumprimento de compromissos, devido ao entendimento prejudicado (Marin e Goés, 2006).

Além dessa limitação, as pessoas com deficiência se deparam no mercado de trabalho com dificuldades relacionadas à educação e ao treinamento profissional pela escassez de programas de reabilitação, sobressaindo a deficiência sobre as habilidades individuais. A alternativa do trabalho informal também se torna uma opção limitada pelos fatores mencionados e pelas dificuldades de acesso ao financiamento, autoconfiança e habilidades comerciais (Corde, 1994).

Entre os 18 e os 65 anos, as pessoas vivem o auge de suas vidas na educação, profissão, casamento e educação dos filhos. De acordo com Erdman (1993), a ocorrência da deficiência auditiva nessa faixa etária pode, direta ou indiretamente, alterar todo um planejamento de vida.

Devido às consequências na comunicação, a participação da família é de grande importância no tratamento e na integração social da pessoa com deficiência auditiva, pois pode colaborar com incentivo e oportunidades de relacionamentos (Rodrigues, 1998). Passaura (2005) lembra, ainda, a tendência histórica no Brasil de o setor privado assumir questões originadas nas condições sociais e econômicas, o que se reflete na família, em que os indivíduos procuram recursos para enfrentar e resolver seus problemas como desemprego, velhice, doenças e deficiências. Na maioria das vezes, as responsabilidades recaem sobre as mulheres, sendo grande parte delas chefes de família.

Dentre os problemas associados à deficiência auditiva, pode ocorrer o isolamento do indivíduo na medida em que ele deixa de pedir para as pessoas repetirem ou falarem mais alto, devido à vergonha e para não se tornar motivo de zombaria ou de desprezo (Erdman, 1993). A negação é uma das reações mais comuns, com alegações de que os outros não articulam bem as palavras, falam baixo ou rápido (Iervolino e col., 2003). Além disso, quando a perda auditiva ocorre gradualmente, a própria limitação não é percebida pelo indivíduo.

Pfeiffer (2002), Nuernberg (2000), Brogna (2005), Sassaki (1997b), entre outros, colocam que o desenvolvimento da cidadania e a conquista de direitos sociais têm construído ao longo da história um quadro de referência para as pessoas com deficiência. Existem muitas leis que garantem o direito da pessoa com deficiência, decretos regulamentares, portarias e resoluções. Merecem destaque a Constituição de 1988 , a Lei $n^{0} 7.853 / 89$, o Decreto $n^{0}$ $3.298 / 99$ e a Lei $n^{0} 10.098 / 2000$, que tratam dos direitos da pessoa com deficiência e sua inclusão de forma mais efetiva. Uma reserva de mercado para as pessoas com deficiência foi estabelecida através da Lei $n^{0} 8.213 / 91$ e nas empresas privadas com mais de 100 empregados (Brasil, 1988, 1989, 1991, 1999, 2000; Souza e Neves, 2005).

A inclusão social tem sido objeto de estudo e discussão, podendo ser entendida num sentido mais amplo, de acordo com Sassaki (1997a), em que a sociedade e as pessoas excluídas buscariam a solução para os problemas, efetivando a equiparação de oportunidades para todos. Para Mendonça (2007), trata-se de um movimento pelo direito de todos os seres humanos participarem da vida pública, sem 
qualquer restrição, sendo então necessário analisar questões como o acesso a educação, saúde, moradia, emprego, renda, lazer, cultura, alimentação e direitos humanos.

Portanto, as concepções sobre inclusão social são relevantes na formulação das políticas públicas e, na área da saúde, inter-relacionam-se com ações e condições de vida da população com deficiência. Para melhor compreender essa relação, na vida de adultos que adquiriram deficiência auditiva e colaborar na formulação e acompanhamento dessas políticas, é importante analisar o contexto em que vivem essas pessoas. Diante disso, o objetivo deste estudo foi analisar as implicações da deficiência auditiva adquirida em adultos, na vida familiar, social e condições de trabalho.

\section{Metodologia}

Este estudo foi aprovado pelo Comitê de Ética e desenvolvido no Hospital de Reabilitação de Anomalias Craniofaciais da Universidade de São Paulo (HRAC/USP), Bauru/São Paulo.

Foi utilizada a abordagem qualitativa, por ter sua preocupação voltada à realidade que não pôde ser quantificada, trabalhando com significados, motivos, aspirações, crenças, valores e fenômenos que não podem ser reduzidos à operacionalização de variáveis (Minayo, 1999). Através dos dados quantitativos foi possível caracterizar o perfil das pessoas com deficiência auditiva adquirida em tratamento no HRAC/USP, descrever e analisar a realidade enfrentada por essa população.

O instrumental para a classificação socioeconômica utilizado pelo Serviço Social da DSA do HRAC foi desenvolvido por Graciano e colaboradores (1999) e tem como finalidade traçar o perfil do paciente e da família, através de sua condição de vida, possibilitando à equipe uma definição adequada do tratamento de acordo com as expectativas e possibilidades de cada paciente. Consiste em um sistema de pontuação e categorização que permite uma aproximação da realidade em que vive a população atendida pela instituição. Resulta, por correlações, em um tipo de classificação por extratos: Baixa Inferior, Baixa Superior, Média Inferior, Média, Média Superior e Alta. Abrange, ainda, os seguintes indicadores: renda, número de membros residentes na família, escolaridade, habitação e ocupação. Dispondo de forma correlacionada, esses indicadores determinarão o número de pontos alcançados e o correspondente estrato da família.

Os sujeitos foram selecionados conforme a disponibilidade de comparecer às entrevistas, observando-se os critérios: serem residentes em Bauru, matriculados no serviço de Saúde Auditiva entre janeiro de 2000 e fevereiro de 2005, terem entre 18 e 60 anos de idade e terem sido diagnosticados com perda auditiva de manifestação súbita dentro dessa faixa etária.

A faixa etária foi estabelecida levando-se em consideração que essa é a época da vida em que o ser humano está em plena capacidade de desenvolvimento e em contato com o mundo. De acordo com os critérios local de residência, faixa etária e época de matrícula, através dos dados cadastrais informatizados, foi levantado um total de 355 sujeitos, cujos prontuários foram analisados para identificar a época e o diagnóstico de deficiência auditiva adquirida de manifestação súbita. Assim, foram selecionadas 27 pessoas, das quais 16 aceitaram e participaram do estudo.

$\mathrm{Na}$ entrevista para a coleta de dados o roteiro buscou estabelecer um diálogo entre sujeito e entrevistadora, para que as respostas retratassem com a máxima fidelidade o objetivo da pesquisa. A entrevista foi baseada nas seguintes hipóteses: a deficiência auditiva adquirida altera as relações sociais e a relação familiar, promovendo a desagregação ou a união; as pessoas com deficiência auditiva adquirida perdem oportunidade ou encontram dificuldade para a colocação no mercado de trabalho.

Para a realização das entrevistas foram estabelecidos critérios em relação aos informantes: a própria pessoa com deficiência auditiva adquirida seria o informante; o cônjuge ou um membro da família (maior de 14 anos) auxiliaria se houvesse dificuldade de comunicação; apenas o cônjuge ou um membro da família (maior de 14 anos) seria o informante, na impossibilidade de a pessoa com deficiência sêlo ou estar ausente. Seguindo esses critérios, seis pacientes foram entrevistados sem acompanhante, três pacientes foram acompanhados pelo cônjuge e um acompanhado pela filha, cinco entrevistas foram 
realizadas somente com os cônjuges e uma somente com o filho.

Para a organização da análise dos dados foi utilizada a técnica de análise de conteúdo elaborada por Bardin (1977). Essa organização compreende três fases: a pré-análise, a exploração do material e o tratamento dos resultados, a inferência e a interpretação.

\section{Resultados e Discussão}

\section{Caracterização das pessoas com deficiência au- ditiva adquirida}

As informações obtidas no cadastro informatizado e nos prontuários clínicos mostraram que 62,5\% dos sujeitos eram homens e 37,5\% mulheres. Com relação à idade, na época da entrevista, encontrouse uma maior concentração na faixa etária de 40 a 49 anos (43,75\%) e uma menor na de 60 a 69 anos $(25,0 \%)$.
Na variável escolaridade, uma das determinantes de inclusão social, verificou-se que $62,5 \%$ dos sujeitos não concluíram o ensino fundamental, sendo $12,5 \%$ analfabetos. Concluíram o ensino médio $25 \%$ e o ensino superior, $6,25 \%$.

De acordo com o instrumental do Serviço Social, desenvolvido por Graciano e colaboradores (1999), que avalia a situação socioeconômica familiar em seu contexto, $62,5 \%$ das pessoas com deficiência auditiva adquirida analisadas pertenciam ao estrato Baixo Superior, significando dez famílias de quatro pessoas, em média, com renda de 2 a 4 salários mínimos, com até o ensino fundamental incompleto, com residência própria, mas insatisfatória e formadas por trabalhadores assalariados.

A Tabela 1 mostra a época de instalação do problema, que ocorreu em maior concentração nas idades de 30 a 49 anos em doze casos $(75,0 \%)$, bem como o comprometimento, ou seja, o grau da perda auditiva nas duas orelhas.

Tabela I - Distribuição do $n^{\circ} e \%$ de casos analisados por grau de perda auditiva e lateralidade $e$ idade de ocorrência do problema

\begin{tabular}{|c|c|c|c|c|c|c|c|c|c|c|}
\hline \multirow{2}{*}{ GRAU DE PERDA } & \multicolumn{2}{|c|}{$20-29$} & \multicolumn{2}{|c|}{ 30-39 } & \multicolumn{2}{|c|}{$40-49$} & \multicolumn{2}{|c|}{$50-59$} & \multicolumn{2}{|c|}{ TOTAL } \\
\hline & $\mathrm{N}$ & $\%$ & $\mathrm{~N}$ & $\%$ & $\mathrm{~N}$ & $\%$ & $\mathrm{~N}$ & $\%$ & $\mathrm{~N}$ & $\%$ \\
\hline Leve-Leve & - & - & 1 & 6,25 & - & - & - & - & 1 & 6,25 \\
\hline Leve-Moderado & - & - & - & - & 2 & 12,50 & - & - & 2 & 12,50 \\
\hline Leve-Severo & - & - & - & - & - & - & 1 & 6,25 & 1 & 6,25 \\
\hline Leve-Profundo & 1 & 6,25 & - & - & 1 & 6,25 & - & - & 2 & 12,50 \\
\hline Moderado-Moderado & - & - & 1 & 6,25 & - & - & - & - & 1 & 6,25 \\
\hline Moderado-Profundo & - & - & 1 & 6,25 & 1 & 6,25 & 1 & 6,25 & 3 & 18,75 \\
\hline Severo-Severo & - & - & - & - & - & - & 1 & 6,25 & 1 & 6,25 \\
\hline Profundo-Profundo & - & - & - & - & 1 & 6,25 & - & - & 1 & 6,25 \\
\hline BILATERAL (subtotal) & 1 & 6,25 & 3 & 18,75 & 5 & 31,25 & 3 & 18,75 & 12 & 75,00 \\
\hline Moderado-normal & - & - & 1 & 6,25 & - & - & - & - & 1 & 6,25 \\
\hline Severo-normal & - & - & - & - & 1 & 6,25 & - & - & 1 & 6,25 \\
\hline Profundo-normal & - & - & 1 & 6,25 & 1 & 6,25 & - & - & 2 & 12,50 \\
\hline UNILATERAL (subtotal) & - & - & 2 & 12,50 & 2 & 12,50 & - & - & 4 & 25,00 \\
\hline TOTAL & 1 & 6,25 & 5 & 31,25 & 7 & 43,75 & 3 & 18,75 & 16 & 100,00 \\
\hline
\end{tabular}


De acordo com a Tabela 1, a incidência mais precoce do problema foi na faixa etária de 20 a 29 anos, com um caso de perda bilateral leve em uma orelha e profunda em outra. Um sujeito da faixa de 40 a 49 anos foi o que teve maior comprometimento, dentre os 16 estudados, apresentando grau profundo bilateral. Em geral, verificou-se uma distribuição heterogênea nos graus de comprometimento audi- tivo nas pessoas analisadas, sugerindo diferentes impactos em suas vidas, conforme a capacidade de lidar com o problema.

Outro aspecto importante no que se refere à perda auditiva adquirida em adultos é o tempo decorrido do surgimento do problema, que pode influenciar a adaptação à nova condição. Na Tabela 2 são apresentadas informações sobre os sujeitos analisados.

\section{Tabela 2 - Distribuição do $\mathrm{n}^{\circ}$ e \% de casos analisados por grau de perda auditiva e lateralidade e tempo de instalação do problema}

\begin{tabular}{|c|c|c|c|c|c|c|c|c|}
\hline \multirow{2}{*}{ GRAU DE PERDA } & \multicolumn{2}{|c|}{ I a 4 anos } & \multicolumn{2}{|c|}{529 anos } & \multicolumn{2}{|c|}{10 a 15 anos ou mais } & \multicolumn{2}{|c|}{ TOTAL } \\
\hline & $\mathrm{N}$ & $\%$ & $\mathrm{~N}$ & $\%$ & $\mathrm{~N}$ & $\%$ & $\mathrm{~N}$ & $\%$ \\
\hline Leve-Leve & - & - & I & 6,25 & - & - & I & 6,25 \\
\hline Leve-Moderado & - & - & 1 & 6,25 & 1 & 6,25 & 2 & 12,50 \\
\hline Leve-Severo & - & - & 1 & 6,25 & - & - & I & 6,25 \\
\hline Leve-Profundo & - & - & 1 & 6,25 & 1 & 6,25 & 2 & 12,50 \\
\hline Moderado-Moderado & - & - & - & - & 1 & 6,25 & 1 & 6,25 \\
\hline Moderado-Profundo & 1 & 6,25 & 1 & 6,25 & I & 6,25 & 3 & 18,75 \\
\hline Severo-Severo & 1 & 6,25 & - & - & - & - & I & 6,25 \\
\hline Profundo-Profundo & - & - & - & - & 1 & 6,25 & I & 6,25 \\
\hline BILATERAL & 2 & 12,50 & 5 & 31,25 & 5 & 31,25 & 12 & 75,00 \\
\hline Moderado-normal & 1 & 6,25 & - & - & - & - & 1 & 6,25 \\
\hline Severo-normal & I & 6,25 & - & - & - & - & I & 6,25 \\
\hline Profundo-normal & 2 & 12,50 & - & - & - & - & 2 & 12,50 \\
\hline UNILATERAL & 4 & 25,00 & - & - & - & - & 4 & 25,00 \\
\hline TOTAL & 6 & 37,50 & 5 & 31,25 & 5 & 31,25 & 16 & 100,00 \\
\hline
\end{tabular}

Observa-se que em quatro casos (25\%), que são também de menor tempo de perda auditiva, as manifestações são unilaterais. Os demais casos têm perda auditiva bilateral, seis deles $(37,5 \%)$ com perda leve em uma orelha, que poderiam ser considerados menos graves.

Em termos de impacto, de acordo com Vash (1988), aspectos como o tempo e o tipo de deficiência, bem como a aparência, não afetam as pessoas da mesma maneira. A percepção individual e o quanto a deficiência afeta e altera suas vidas é que determinará o impacto, daí a importância de se analisar as relações sociais dessas pessoas.

A compreensão das consequências da deficiência auditiva adquirida na vida da pessoa adulta necessita de uma análise individualizada e global sobre todos os aspectos: idade da ocorrência, causa, tipo de limitação e momento de vida profissional, assim como é necessário que a pessoa acometida e sua família recebam orientação.

\section{Relacionamento familiar}

Os resultados da análise qualitativa das respostas às entrevistas foram organizados de acordo com as relações familiares, relações sociais e situação profissional. As respostas dos pacientes e dos familiares foram apresentadas separadamente.

Na percepção da pessoa com deficiência auditiva adquirida, o relacionamento familiar ficou prejudicado, sendo identificadas alterações importantes no seu comportamento e o desconhecimento do problema por parte do deficiente e dos familiares, 
contribuindo para o agravamento de muitas situações de conflito e estresse. As frases a seguir exemplificam a situação:

E. 18 (pac.) [...] meus filhos, agora eles estão entendendo, mas no começo foi meio difícil... meu filho me chamava [...] na terceira vez que eu ia perceber [...] ficou um pouco mais difícil, né, o relacionamento [...]

E. 17 (pac.): [...] às vezes eu tô procurando uma coisa lá: além de ser surdo é cego [...] porque às vezes ela fala alguma coisa eu não entendo, aí ela grita alto: aí eu esqueci que você surdo [...]

E. 11 (рас.): [...] aí chegou dois cunhado meu e falou, nós vamos levarvocê pra casa do seu pai, eu tava meio bobão com tanto remédio [...] puseram eu na casa do meu pai e deixaram eu lá... vai fazer 6 anos que eu não vejo mais [referindo-se ao cônjuge e aos filhos]

Vários autores relatam o impacto da deficiência na família. Neste estudo, diante dos relatos encontrados, é bastante significativa a afirmação de Buscaglia (1997) sobre o processo de interação, em que somos influenciados e influenciamos e as constantes mudanças que significam a introdução de outros padrões que deverão ser apreendidos. Até que ocorram, motivarão situações que remetem ao isolamento, à exploração da própria condição pelo deficiente ou a um potencial desprezo dos familiares, como as situações descritas.

Quando a deficiência se instala na vida adulta, o cônjuge, os filhos e os parentes próximos serão mais afetados (Vash, 1988). Assim, a estabilidade emocional torna-se essencial para enfrentar as dificuldades e facilitar o processo de ajustamento e algumas habilidades podem ser exigidas ao máximo, levando a família ao estresse .

As respostas dos familiares a respeito das alterações vivenciadas mostraram dificuldade de aceitação, rejeição, falta de paciência e desconhecimento do problema, que levam à desagregação familiar e constituem uma forma de exclusão social.

E. 8 (filha): [...] foi difícil de acostumar [...] o ouvido é mais difícil, você fala uma coisa ele entende outra [...] ele não era estressado como ele é hoje, hoje vive na base do calmante, tem que ter muita paciência com ele, ele deixa a gente muito fora de si tem hora [...]

E. 6 (cônj.): [...] uns dois meses para trás nós quase no separamos, foi por esta convivência difícil. Muito ciúme, ele não entende não ouve, eu vou explicar para ele detalhes ele fala, você está mentindo [...] eu fui internada nesta época [...] estresse profundo, a pressão subiu demais [...]

\section{As relações sociais}

De acordo com o relato dos próprios entrevistados com deficiência auditiva, foi possível verificar que eles passaram a enfrentar os mais diferentes tipos de dificuldades no relacionamento social, dentre os quais discriminação, vergonha do problema e isolamento.

E. 16 (pac.): [...] começa a tratar diferente [...] passa a gritar com você sendo que não há necessidade [...] já vi muita gente olhar estranho pra mim, quando vê eu de aparelho [...] tão bonita, tão nova usando aparelho [...]

E. 18 (pac.): [...] o relacionamento com os amigos, com os parentes eu faço o máximo para ninguém perceber [...] muitas pessoas nem sabem que eu tenho essa perda auditiva [...]

Preconceito e atitudes discriminatórias para com as pessoas com algum tipo de deficiência, que podem ser vistas como dependentes, foram relatadas por Souza e Neves (2005) como algo comum na sociedade. Esse comportamento está relacionado ao desconhecimento do problema e da capacidade da pessoa com deficiência.

Buscaglia (1997) destaca que os próprios deficientes têm sua parcela de responsabilidade, devendo superar dificuldades, reconhecer suas capacidades, enfrentar conflitos e preocupações, sem sucumbir a sentimentos. A aceitação do problema é essencial para a compreensão e o enfrentamento da deficiência.

Vash (1988) considera que interferem nessa disponibilidade emocional para a adaptação à nova situação o tempo de instalação da deficiência, o tipo de problema, as funções afetadas, o grau de severidade, a aparência, o estilo de vida e o momento profissional na aquisição da deficiência, ou seja, a forma como ela é percebida e o que a pessoa deixará de fazer. 
Neste estudo, a presença de perdas unilaterais (4 pessoas) e perdas leves em pelo menos uma orelha (5 pessoas), associadas à invisibilidade da deficiência auditiva, a não ser quando o aparelho de amplificação sonora individual (AASI) está sendo usado, facilita que o problema seja escondido ou disfarçado, embora a comunicação fique comprometida e possa levar ao isolamento. A não aceitação, mesmo em graus menos graves de comprometimento auditivo, traz consequências que podem ser danosas à vida da pessoa.

E. 2 (pac.): [...] eu já não conseguia mais conversar com várias pessoas ao mesmo tempo [...]

E. 10 (pac.): [...] eu acabei me intimidando, me restringindo, fiquei insociável, fiquei quieto num canto, num conversava mais ou eu conversava com uma pessoa só ou não conversava com ninguém [...]

Eventos que parecem comuns para a pessoa com deficiência auditiva são constrangedores, conforme pesquisa realizada por Marin e Góes (2006). A dificuldade de comunicação no grupo social tem como consequência o isolamento ou o abandono dos amigos, problema que pode ser amenizado mediante orientações especializadas e acompanhamento (Iervolino e col., 2003).

Na percepção dos familiares, os relatos são significativos sobre as dificuldades enfrentadas no meio social, e contribuem para o entendimento da exclusão vivenciada pelos deficientes auditivos, questões relevantes como: a discriminação do outro, a vergonha do problema, a dificuldade de relacionamento, a alteração de comportamento, irritação, nervosismo, insegurança e dependência.

A vergonha de pedir às pessoas que repitam o que falaram ou que falem mais alto faz com que o deficiente seja vítima de zombarias, o que contribui para o isolamento e o desenvolvimento de situações de estresse, cobrança de si próprio e ansiedade (Erdman, 1993). A vergonha acentua-se conforme o grau de dificuldade de comunicação: se a dificuldade de comunicação é menor, o problema pode não ser exposto, o aparelho auditivo ocultado sob o cabelo ou não colocado, na tentativa de enfrentar as outras pessoas num nível de igualdade (Buscaglia, 1997).
As alterações de comportamento, o afastamento e a vergonha, descritos por Vash (1988), Buscaglia (1997), Erdman (1993), Boéchat e colaboradores (2003), revelam a importância do entendimento desses aspectos ao se considerar o problema da pessoa com deficiência e seu relacionamento social. Esses autores reforçam a necessidade de acompanhamento profissional especializado para os familiares, a fim de eles não dificultarem ainda mais a vida do deficiente, que, bem orientado, desenvolverá melhor a aceitação e a superação dos problemas decorrentes da deficiência.

E.1o (cônj.): [...] quem não conhece bem ele a fundo não percebe, ele não deixa perceber que ele tem problema, ele tem um pouco assim de vergonha [...] eu tenho a impressão que ele não ouve muito bem o que os outros falam, então ele procura não conversar e às vezes dá até a impressão de que ele é meio antipático [...]

E. 8 (filha) [...] só vai na casa... da minha tia ou de algum parente [...] não fica muito tempo, ninguém consegue ficar muito tempo perto dele... eles falam que só a gente pra aguentar ele [...]

Marin e Góes (2006) constataram que nas atividades do cotidiano as relações interpessoais são restritas em espaços de comunicação oral, e as pessoas com deficiência auditiva acabam dependendo da companhia de um ouvinte. Daí os sentimentos de dependência e inferioridade, indicativos de exclusão social.

E. 6 (cônj.): [...] eu sou intérprete dele. Porque mesmo com um aparelhinho ele sente dificuldade bastante [...]

\section{Exclusão e inclusão social no contexto do trabalho}

Com a deficiência auditiva adquirida na vida adulta uma das áreas mais afetadas é a relacionada ao trabalho, pois é considerada uma linguagem, uma categoria antropológica, faz parte da especificidade do ser humano, em que a noção de vínculo social se baseia na reciprocidade ou na utilidade social (Méda, 1998). A ocorrência de uma deficiência pode interferir de forma negativa nesse processo, pois é através do trabalho que o ser humano se sente útil, necessário e integrado à vida social. 
As dificuldades para compreender regras, rotinas e obrigações e para se comunicar com chefes e colegas fazem parte do que a pessoa com deficiência auditiva vai enfrentar (Marin e Góes, 2006).

Dos sujeitos pesquisados, 13 (81,25\%), exerciam ocupação remunerada na época da ocorrência do problema auditivo. Desses, sete $(53,85 \%)$ continuaram na mesma profissão: bibliotecária, caixa, motorista, operário, mecânico, auxiliar administrativo e auxiliar de serviços gerais. Outros quatro (30,77\%) pararam de trabalhar: dois se demitiram (um já era aposentado), um se aposentou e outro solicitou auxílio-doença. Esses quatro indivíduos apresentavam, em pelo menos uma orelha, perda de grau severo ou profundo. Os dois últimos casos mudaram de profissão: um tinha perda leve e mudou de profissão após ser demitido, e o outro mudou por orientação médica devido ao ambiente ruidoso.

Observou-se que mais da metade das pessoas que estavam trabalhando permaneceu na mesma profissão e $46,15 \%$ tiveram alterações na situação de trabalho (Tabela 3).

Antes da deficiência auditiva, apenas três $(18,75 \%)$ mulheres estavam fora do mercado de trabalho formal e depois do problema auditivo somaramse a elas quatro pessoas que deixaram de trabalhar, totalizando sete (43,75\%) dos entrevistados.

A pessoa que mudou de profissão, de serralheiro para vendedor, devido ao ambiente de trabalho ruidoso que poderia prejudicar ainda mais sua audição, foi o caso de ocorrência mais precoce, na faixa etária de 20 a 29 anos, com perda bilateral leve e profunda. Já o caso com maior comprometimento, ocasionado por trauma cranioencefálico, na faixa de 40 a 49 anos, com grau profundo bilateral, tratava-se de um auxiliar de serviços gerais, que, após o problema, pôde voltar à sua ocupação.

Para os entrevistados que estavam inseridos no mercado de trabalho no momento da deficiência, uma das consequências imediatas foi o afastamento da atividade.

\section{Tabela 3 - Distribuição do $n^{\circ}$ e \% de casos analisados que tiveram modificação na situação profissional após a deficiência}

\begin{tabular}{|c|c|c|c|c|}
\hline SITUAÇÃO PROFISSIONAL & ANTES DA DEFICIÊNCIA & APÓS A DEFICIÊNCIA & $\mathrm{N}$ & $\%$ \\
\hline Pararam de trabalhar & $\begin{array}{l}\text { Comerciante autônomo. } \\
\text { Motorista } \\
\text { Motorista } \\
\text { Cuidadora }\end{array}$ & $\begin{array}{l}\text { Aposentou-se } \\
\text { Auxílio doença } \\
\text { Pediu demissão / já aposentado } \\
\text { Pediu demissão }\end{array}$ & $\begin{array}{l}1 \\
1\end{array}$ & $\begin{array}{l}7,69 \\
7,69 \\
7,69 \\
7,69\end{array}$ \\
\hline Subtotal & & & 4 & 30,77 \\
\hline Mudaram de profissão & $\begin{array}{l}\text { Representante comercial } \\
\text { Serralheiro autônomo. }\end{array}$ & $\begin{array}{l}\text { Foi demitido/mudou } \\
\text { Mudou }\end{array}$ & $\begin{array}{l}1 \\
1 \\
\end{array}$ & $\begin{array}{l}7,69 \\
7,69 \\
\end{array}$ \\
\hline Subtotal & & & 2 & 15,38 \\
\hline TOTAL & & & 6 & 46,15 \\
\hline
\end{tabular}

Questões relacionadas a profissionais de saúde, como orientação inadequada, despreparo diante do problema, ausência de mecanismos de encaminhamento e readaptação, foram vivenciadas pelos entrevistados, somando-se à frustração diante dos obstáculos e levando ao afastamento ou ao retorno à mesma função, assumindo os riscos ocupacionais em função de suas necessidades.
E. 8 (pac.): [...] ele não quis dar outro serviço para mim [...] mandou eu para o INSS [...] faz 5 anos e não aposentou ainda [...]

E. 2 (pac.): [...] quando eu perdi a audição o médico mandou eu me afastar de barulho, então eu tive que mudar de profissão [...] parti pra vendas, acabou não dando certo [...] então é melhor arriscar a perder um ouvido mas ser feliz fazendo 
o que eu gosto... do que viver em uma situação que não dá satisfação... não estou vivendo, estou apodrecendo [...]

Também para enfrentar o mercado de trabalho identifica-se a discriminação do empregador e o desconhecimento sobre a deficiência auditiva que levam a situações como de exploração da deficiência, ou sinônimo de incapacidade.

As exigências quanto à qualificação, a competição pelas vagas, o índice de desemprego no país e o nível de escolaridade afetam mais intensamente a contratação da pessoa com deficiência (Jaime e Carmo, 2005). Como alternativa encontram-se as relações de amizade, em que a cobrança é superada ou a pessoa passa a exercer atividades que podem estar aquém de sua capacidade.

E.11 (pac.): [...] você vai hoje fazer uma ficha...vai com o aparelho no ouvido a pessoa já olha você meio torto assim... não posso esconder, você vai fazer uma audiometria vai aparecer lá... se você tem um trabalho pra ganhar... quinhentos reais, a pessoa vê que você tem aparelho no ouvido, pode falar: eu vou pagar trezentos reais... quando eu me recuperei, quem me deu o primeiro emprego foi a K., porque lá me conheciam desde os 14 anos, não pediram audiometria, não pediram nada [...]

E. 2 (pac.): [...] como eu não tinha nenhuma outra profissão, vou partir pra vendas que é o mais comum [...] eu chegava nas pessoas já atrapalhava [...] dava raiva de não conseguir desempenhar [...]

Ao perder a colocação no mercado de trabalho, a situação financeira da pessoa com deficiência é alterada, afetando a dinâmica familiar e gerando conflitos com familiares e conhecidos e dependência. A dificuldade de encontrar uma ocupação, qualquer que seja, além do serviço indesejado, renda insuficiente, autoestima afetada, sensação de incapacidade, acaba gerando frustração.

Neste estudo, as situações encontradas na condição da pessoa com deficiência auditiva adquirida destacaram falta de autoconfiança e de autoestima, baixa escolaridade, despreparo profissional, dependência da caridade do outro, ou seja, uma bagagem individual pobre, que se somada à deficiência trouxe limitações funcionais, perpetuando ou piorando as relações sociais e a situação econômica e emocional.

Para os familiares, em relação ao trabalho, um dos problemas apontados foi a perda da colocação devido à deficiência, assim como a falta de paciência dos empregadores. As pessoas enfrentam não só dificuldades pessoais, mas também aquelas criadas pela sociedade. Alguns empregadores têm receio de empregar uma pessoa com deficiência por não conhecerem suas aptidões e talentos e confundirem deficiência com doença (Souza e Neves, 2005). Assim, os sentimentos de incapacidade, frustração, rejeição, apatia e a alienação imposta pela deficiência auditiva instalam-se na vida das pessoas.

E. 1 (cônj.): [...] perdeu a vontade para tudo [...] trabalhou muito tempo registrada... ela que pediu a conta [...] reclamava quando trabalhava... as pessoas perdiam a paciência de chamar ela, $e$ acho que ela percebia isso, então ela se achava numa posição inferior [...]

E. 2 (cônj.): [...] falou que se sentiu assim inútil, porque ele falou: meu Deus e agora né? [...] ele sentiu rejeição [...]

Segundo Buscaglia (1997), a deficiência é um fenômeno social que leva a discriminação, rejeição e atribuição de um status social inferior. Esses problemas podem ser vivenciados diariamente, quer ocorram de forma dissimulada ou não, reforçando a ideia da sociedade de pena e caridade; nesses casos o surdo não se opõe, mas se vê subordinado à marginalização da qual é vítima.

Atitudes desrespeitosas com trabalhadores com deficiência causam humilhação e podem levar ao afastamento (Jaime e Carmo, 2005). Em relação à deficiência auditiva, pode ser exigida maior atenção nas tarefas, demorando mais na sua execução e refletindo em estresse para o trabalhador (Erdman, 1993). Portanto, um maior preparo das pessoas com deficiência auditiva adquirida e esclarecimento aos empregadores e à sociedade, em geral, são essenciais para a mudança na condição de vida desses trabalhadores.

A adequação pessoal de cada um ao grau de frustração pode variar, podendo se tornar uma 
fonte de descoberta de soluções e de alternativas gratificantes.

E. 2 (cônj.) [...] hoje ele é técnico em manutenção industrial [...] eu creio que ele deu a volta por cima [...] ele ficou acho que uns cinco anos fazendo um curso atrás do outro... se aperfeiçoando [...] hoje a eficiência dele é maior do que a deficiência auditiva [...]

\section{Considerações Finais}

As pessoas com deficiência compõem um grupo social heterogêneo, sobre o qual recaem, ao longo da história da humanidade, o estigma, o preconceito, a rejeição e a discriminação, as quais necessitam de uma proposta integrada de políticas públicas de atenção. Diante disso, este estudo teve por objetivo analisar as implicações da deficiência auditiva adquirida em adultos, na vida familiar, social e no trabalho, através da percepção dessas pessoas e de seus familiares, a fim de conhecer uma parte de sua realidade.

Os dados quantitativos mostraram que a deficiência auditiva adquirida afetou mais homens, na faixa etária de 40 a 49 anos, com baixa escolaridade e pertencentes à classe socioeconômica Baixa Superior. O comprometimento auditivo ocorreu do grau leve ao profundo, uni ou bilateral, ocasionando diferentes impactos em suas vidas.

Sendo a comunicação uma necessidade vital do ser humano, o elo que mantém a pessoa ativa no seu meio social e familiar; a diminuição dessa capacidade gera complicações e situações constrangedoras. Recursos existentes, como os AASI, podem atenuar as dificuldades, mas para muitas pessoas permanecem as próprias barreiras de aceitação do problema.

A discriminação e a vergonha se fizeram muito presentes nas vidas dos sujeitos analisados, contribuindo para sua exclusão social, mostrando a dificuldade de adaptação, a frustração, o isolamento e a depressão, impactos que emergiram nas entrevistas, seja pela autodiscriminação, discriminação familiar e social e alterações no relacionamento.
Dentre as dificuldades encontradas, foi possível avaliar nos relatos dos entrevistados o estresse e a desagregação familiar. Alterações importantes ocorreram também na situação de trabalho, área de adaptação mais difícil para o adulto que se torna deficiente, pois reflete em sua segurança social e econômica. Analisados em conjunto, esses dados sugerem que a compreensão das consequências da deficiência auditiva adquirida em adultos necessita de uma análise individual e global.

Ressalte-se que os entrevistados fazem parte de um grupo que teve acesso a um atendimento especializado, o que ainda não é uma realidade para grande parte da população brasileira, apesar da Política Nacional de Atenção à Saúde Auditiva implantada a partir de 2004 (Brasil, 2004). Constata-se a existência de legislação que ampara o deficiente, mas levará um tempo para que seja assimilada pela sociedade e pela própria pessoa com deficiência. $\mathrm{O}$ reconhecimento da sua capacidade e potencialidade depende de estratégias como recursos para reabilitação e divulgação de conhecimentos, que garantam acesso à vida em comum na sociedade. Esses são os desafios numa sociedade ouvinte-majoritária.

As considerações deste trabalho não se esgotam, mas os dados levantados podem alertar os profissionais de saúde sobre o assunto, contribuir para a implantação de medidas de prevenção e atenção à deficiência auditiva adquirida na vida adulta e no subsídio de políticas públicas de saúde nesse setor.

\section{Referências}

BARDIN, L. Análise de conteúdo. Lisboa: Edições 70, 1977 .

BOÉCHAT, E. M.; RUSSO, I. C .P.; ALMEIDA, K. Reabilitação do adulto deficiente auditivo. In: ALMEIDA, K.; IÓRIO, M.C.M. Próteses auditivas: fundamentos teóricos e aplicações clínicas. 2. ed. São Paulo: Lovise, 2003. p. 437-446.

BRASIL. Constituição da República Federativa do Brasil: promulgada em 5 de outubro de 1988. São Paulo: Saraiva, 2001. 
BRASIL. Lei n. $7853 / 89$ de 24 de outubro de 1989. Dispõe sobre o apoio às pessoas portadoras de deficiência, sua integração social, sobre a Coordenadoria Nacional para Integração da Pessoa Portadora de Deficiência - Corde, institui a tutela jurisdicional de interesses coletivos ou difusos dessas pessoas, disciplina a atuação do Ministério Público, define crimes, e dá outras providências. Disponível em: <http://www. planalto.gov.br/ccivil/LEIS/L7853.htm>. Acesso em: 3 nov. 2007.

BRASIL. Decreto n. 3.298/99 de 20 de dezembro de 1999. Regulamenta a Lei n. 7.853 de 24 de outubro de 1989, dispõe sobre a Política Nacional para a Integração da Pessoa Portadora de Deficiência, consolida as normas, e dá outras providências. Disponível em: <https://www.planalto.gov.br/ ccivil_o3/decreto/D3298.htm >. Acesso em: 3 nov. 2007.

BRASIL. Lei ${ }^{0} 10.098 / 2000$ de 19 de dezembro de 200o. Estabelece normas gerais e critérios básicos para a promoção da acessibilidade das pessoas portadoras de deficiência ou com mobilidade reduzida, e dá outras providências. Disponível em: <http://www.planalto.gov.br/ccivil/LEIS/L1oog8. htm>. Acesso: em 3 nov. 2007.

BRASIL. Lei n. 8.213/91 de 24 de julho de 1991. Dispõe sobre os planos de benefícios da Previdência Social e dá outras providências. Disponível em: <http://www.planalto.gov.br/ ccivil_o3/LEIS/L8213cons.htm>. Acesso em: 3 nov. 2007.

BRASIL. Ministério da Saúde. Portaria GM/MS n. 2073, de 28 de setembro de 2004. Institui a Política Nacional de Atenção à Saúde Auditiva. Disponível em: <http://dtr2oo1.saude.gov.br/ sas/PORTARIAS/Port2004/GM/GM-2073.htm>. Disponível em: 3 nov. 2007.

BROGNA, P. El derecho a la igualdad... ¿O el derecho a la diferencia? El Cotidiano, México, DF, v.21, n.134, p. 43-55, 2005.

BUSCAGLIA, L. F. Os deficientes e seus pais. 3. ed. Rio de Janeiro: Nova Era, 1997.
CORDE - Coordenadoria Nacional para Integração da Pessoa Deficiente. Oportunidade de trabalho para portadores de deficiência: um guia para as organizações de empregadores. Brasília, DF: OIT,CORDE, 1994.

ERDMAN, S. A. Counseling hearing impaired adults. In: ALPINER, J. G.; MACCARTHY, P. A. Rehabilitative audiology: children and adults. Baltimore: Williams \& Wilkins, 1993. p. 374-413.

GALINDO, C. A surdez súbita. Disponível em: <http://www.drashirleydecampos.com.br/ noticias/12670>. Acesso em: 3 nov. 2007.

GRACIANO, M. I. G.; LEHFELD, N. A .S.; NEVES FILHO, A. Critérios de avaliação para classificação sócio-econômica: elementos de atualização II. Serviço Social e Realidade, Franca; v. 8, n. 1, p. 109128, 1999.

IBGE - INSTITUTUTO BRASILEIRO DE GEOGRAFIA E ESTATÍSTICA. Sistema IBGE de Recuperação Automática - SIDRA. Censo demográfico 20oo: resultados do universo população residente, por tipo de deficiência, segundo o sexo e grupos de idade - Brasil. Tabela. Disponível em:< www.sidra.ibge.gov.br/cd/ cd200ocgp.asp?o=7\&i=p >. Acesso em: 3 nov. 2007.

IERVOLINO, S. M .S.; CASTIGLIONI, M.; ALMEIDA, K. A orientação e o aconselhamento no processo de reabilitação auditiva. In: ALMEIDA, K.; IORIO, M. C. M. Próteses auditivas: fundamentos teóricos e aplicações clínicas. 2. ed. São Paulo: Lovise, 2003. p. 421.

JAIME, L. R.; CARMO, J. C. A inserção da pessoa com deficiência no mundo do trabalho: o resgate de um direito de cidadania. São Paulo: MaxPrint Editora e Gráfica, 2005.

MARIN, C. R.; GÓES, M. C. R. A experiência de pessoas surdas em esferas de atividade do cotidiano. Cadernos CEDES, Campinas, v. 26, n. 69, p. 231-249, 2006.

MÉDA, D. El trabajo. Barcelona: Gedisa, 1998. 
MENDONÇA, E. Inclusão social: seu papel na transformação da sociedade. Revista Mercado. Disponivel em: <http://www.revistamercado.com. $\mathrm{br} / \mathrm{mercado.qp}$ s/Ref/RHSR-6QGQVF>. Acesso em: 15 fev. 2007.

MINAYO, M. C. S. O desafio do conhecimento: pesquisa qualitativa em saúde. 6. ed. São Paulo: Hucitec, 1999.

MORITA, I. A questão do trabalho: análise conceitual de uma variável fundamental na reprodução social. Ciências Sociais Unisinos, São Leopoldo, v. 41, n. 2, p. 82-88, 2005.

NUERNBERG, A. H. Os labirintos da defesa do "direito à diferença". Ponto de Vista, Florianópolis, v. 2, n. 2, p. 61-63, 2000. Resenha.

PASSAURA, L.A família na contemporaneidade e os impactos sociais. Serviço Social \& Realidade, Franca, v. 14, n. 2, p. 197-208, 2005.

PASSOS, O. O. Interdisciplinaridade e surdez. In: Congresso Internacional, 3; Seminário Nacional do INES, 9., 2004, Rio de Janeiro. Educação de surdos: múltiplas faces do cotidiano escolar. Anais... Rio de Janeiro: Instituto Nacional de Educação de Surdos, 2004. p. 142.

PFEIFFER, D. The philosophical fundations of disability dtudies. Disability Studies Quarterly, New York, v. 22, n. 2, p. 3-23, 2002.

RODRIGUES, A. F. P. Intervenção do serviço social junto a casos de abandono de tratamento: relações de parceria entre o HRACF e promotoria. Bauru: USP, Hospital de Reabilitação de Anomalias Crânio Faciais, 1998. Relatório Final FUNCRAF, período de abril/1997 a junho 1998.

RUSSO, I. C. P., ALMEIDA, K. O processo de reabilitação audiológica do deficiente auditivo idoso. In: MARCHESAN, I. Q. (Org.). Tópicos em fonoaudiologia. São Paulo: Lovise, 1995. p. 429446.
RUSSO, I. C. P.; SANTOS, T. M. M. A prática da audiologia clínica. 4. ed. São Paulo: Cortez, 1993.

SASSAKI, R. K. Abordagens sócio-antropológicas em educação especial. In: SKLIAR, C. (Org.). Educação e exclusão. Porto Alegre: Editora Mediação, 1997a.

SASSAKI, R. K. Inclusão: construindo uma sociedade para todos. Rio de Janeiro: WVA, 1997b.

SOUZA, V. C.; NEVES, N. P. Enfrentando o mundo do trabalho: relatos orais de pessoas com deficiências. Serviço Social \& Realidade, Franca, v. 14, n. 2, p. 1-258, 2005.

VASH, C. L. Enfrentando a deficiência: a manifestação, a psicologia, a reabilitação. São Paulo: Pioneira : Edusp, 1988.

WHO - World Health Organization . Grades of hearing impairment. [online]. 2006a. Disponível em: http://www.who.int/pbd/deafness/hearing impairment_grades/en/ print. html. Acesso em: 22 mai. 2006.

WHO - World Health Organization . Prevencion of deafness and hearing impairment. [online]. 2006b. Disponível em: http://www.who.int/pbd/deafness/ hearing_impairment_grades/en/ print. html. Acesso em: 26 mai. 2006.

WHO - World Health Organization. Iniqüidades em saúde no Brasil, nossa mais grave doença. [online]. 2006c. Disponível em: http://www. determinantes.fiocruz.br. Acesso em: 10 ago. 2006.

WHO - World Health Organization. Educação de surdos: múltiplas faces do cotidiano escolar. Comissão de Determinantes Sociais. Disponível em: www.determinantes.fiocruz.br. Acesso em: 10 ago. 2006b. 